\title{
Adaptation response of Pseudomonas fragi on refrigerated solid matrix to a moderate electric field
}

\author{
Wenbo Chen ${ }^{1,2}$, Honghai Hu ${ }^{1,2}$, Chunjiang Zhang ${ }^{1,2}$, Feng Huang ${ }^{1,2}$, Dequan Zhang ${ }^{1}$ and Hong Zhang ${ }^{1,2^{*}}$
}

\begin{abstract}
Background: Moderate electric field (MEF) technology is a promising food preservation strategy since it relies on physical properties - rather than chemical additives - to preserve solid cellular foods during storage. However, the effectiveness of long-term MEF exposure on the psychrotrophic microorganisms responsible for the food spoilage at cool temperatures remains unclear.
\end{abstract}

Results: The spoilage-associated psychrotroph Pseudomonas fragi MC16 was obtained from pork samples stored at $7{ }^{\circ} \mathrm{C}$. Continuous MEF treatment attenuated growth and resulted in subsequent adaptation of M16 cultured on nutrient agar plates at $7{ }^{\circ} \mathrm{C}$, compared to the control cultures, as determined by biomass analysis and plating procedures. Moreover, intracellular dehydrogenase activity and ATP levels also indicated an initial effect of MEF treatment followed by cellular recovery, and extracellular $\beta$-galactosidase activity assays indicated no obvious changes in cell membrane permeability. Furthermore, microscopic observations using scanning and transmission electron microscopy revealed that MEF induced sublethal cellular injury during early treatment stages, but no notable changes in morphology or cytology on subsequent days.

Conclusion: Our study provides direct evidence that psychrotrophic $P$. fragi MC16 cultured on nutrient agar plates at $7{ }^{\circ} \mathrm{C}$ are capable of adapting to MEF treatment.

Keywords: Adaptation response, Moderate electric field, Nutrient agar plates, Psychrotrophic microorganisms, Pseudomonas fragi, Solid cellular foodstuffs

\section{Background}

Alternating electric fields stall the planktonic growth of several prokaryotic microorganisms, such as Escherichia coli, Lactobacillus acidophilus, Staphylococcus aureus, Bacillus cereus, Pseudomonas putida, and P. fluorescens [1-6], leading to its recent application in food preservation [7]. The effectiveness of alternating electric field technology in preventing spoilage can be easily assessed by analyzing the amount of proteins eluted from cellular samples [7]. Alternating electric fields are generally used at either high intensity or high frequencies $[1,3,4,7,8]$,

\footnotetext{
* Correspondence: zhang.h07@hotmail.com

${ }^{1}$ Institute of Food Science and Technology, Chinese Academy of Agricultural Sciences/Key Laboratory of Agro-Products Processing, Ministry of Agriculture, Beijing 100193, People's Republic of China

${ }^{2}$ College of Staple Food Technology, Chinese Academy of Agricultural

Sciences, Institute of Food Science and Technology, Harbin 151900, People's Republic of China
}

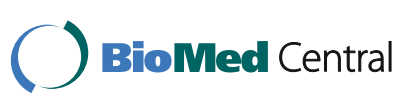

(c) The Author(s). 2017 Open Access This article is distributed under the terms of the Creative Commons Attribution 4.0 International License (http://creativecommons.org/licenses/by/4.0/), which permits unrestricted use, distribution, and reproduction in any medium, provided you give appropriate credit to the original author(s) and the source, provide a link to the Creative Commons license, and indicate if changes were made. The Creative Commons Public Domain Dedication waiver (http://creativecommons.org/publicdomain/zero/1.0/) applies to the data made available in this article, unless otherwise stated. fields (MEFs, typically $<1-100 \mathrm{~V} / \mathrm{cm}$ ) at low frequencies (1-100 Hz) have been far less studied [9]. For example, planktonic $L$. acidophilus exhibits a decreased lag time following treatment with a MEF [6, 9], causing a marked increase in bacteriocin yield [6]. However, few studies have investigated the application of MEF as a food preservative.

Refrigeration is a common food preservation strategy that extends the shelf life of food products by decreasing microbial growth rates and slowing the physical and chemical reactions responsible for spoilage [10-12]. However, microbial species adapted to the temperatures ranging from $0{ }^{\circ} \mathrm{C}$ to $22{ }^{\circ} \mathrm{C}$ (e.g., psychrotrophs) outcompete other microorganisms and dominate the microbial population present on food products during refrigerated storage [12-14], and thus are the primary contributors to food spoilage at refrigeration temperatures [15-19]. 
Pseudomonas fragi is a psychrotrophic species responsible for the majority of spoilage of meat stored aerobically at refrigeration temperatures [17]. P. fragi is more widely distributed than other pseudomonads, and has been isolated from water, soil, plant materials, and other natural media [17, 20-22]. This species grows well at temperatures ranging from $2{ }^{\circ} \mathrm{C}$ to $35{ }^{\circ} \mathrm{C}$ [21]. The prevalence and growth conditions of $P$. fragi contribute to its successful proliferation on foods, especially fresh meat $[12,17,21,23,24]$, and the strict chill chain applied during fresh meat production from slaughtering to final distribution selectively favors its development $[21,25]$. Moreover, P. fragi is suggested to promote the growth and survival of several foodborne pathogens, such as S. aureus and Listeria monocytogenes [26, 27]. Therefore, information about $P$. fragi growth and biological responses to preservation conditions during food storage is urgently needed to improve food safety.

MEF technology may provide a means to control microbial growth on food products where refrigeration fails to do so. However, organisms may develop adaptive responses to continuous MEF treatment, similar to how $P$. fragi has adapted to cooler temperatures [21]. Thus, the aim of this work was to investigate the biological responses of psychrotrophic microorganisms to continuous MEF treatment by characterizing the adaptive response to MEF treatment in $P$. fragi. Additionally, we examined cell structural changes induced by MEF treatment using electron microscopy.

\section{Methods}

\section{Meat sample preparation and storage}

Pork samples were prepared as described by Ercolina et al. [24] with some modifications. Pork muscle (Longissimus dorsi) obtained from a slaughterhouse was cut into similar-sized pieces $(2 \times 2.5 \times 3 \mathrm{~cm})$ and packed in sterile stomacher bags (Labplas, Inc., Sainte-Julie, Quebec,
Canada). The prepared samples were then stored aerobically at $7{ }^{\circ} \mathrm{C}$ for at least 5 days and used as sources for the isolation of psychrotrophs $[12,26]$.

\section{Bacterial strain isolation and identification}

A meat sample (25 g) was aseptically weighed and homogenized in $225 \mathrm{~mL}$ of peptone saline $(0.85 \% \mathrm{NaCl}$ and $0.1 \%$ peptone in distilled water) at room temperature $\left(22-25^{\circ} \mathrm{C}\right)$ [27-29]. Serial dilutions were prepared with the homogenized meat sample and $100 \mu \mathrm{L}$ aliquots of the appropriate dilutions were spread in triplicate on nutrient agar plates (Luqiao Co., Beijing, China) and incubated for 5 days at $7{ }^{\circ} \mathrm{C}$ [24]. Colonies present on the countable plates were randomly picked and further purified by repeated streaking. Finally, these purified cultures were maintained as glycerol stock culture and stored at $-80{ }^{\circ} \mathrm{C}$ [30]. These isolates were also deposited on nutrient agar slants in the dark at $4{ }^{\circ} \mathrm{C}[31]$.

The isolates were identified by $16 \mathrm{~S}$ rDNA sequencing carried out by Sangon Biological Co., Ltd. (Shanghai, China).

\section{MEF system}

The MEF system used in this study was designed and patented by Takayuki et al. [32]. The system consisted of an input controller, transformer, feedback control circuit, output controller, and discharge plate. The transformed voltage was exerted on the discharge plate via the output controller, which could make the discharge plate generate a wide range of electric fields [32]. The waveform of the output voltage measured with an oscilloscope (UTD2102CEX, Uni-Trend) and a high-voltage prober (P6015A, Tektronix) is a sine wave with a $9.2 \mathrm{kV}$ maximum voltage (peak-to-peak). The frequency of the output voltage is 50 $\mathrm{Hz}$ (as described in $[6,9]$ ) and identical to that of the input voltage. Other parameters are identical to those described in the patent [32]. The schematics of this apparatus and the refrigeration system are shown in Fig. 1.

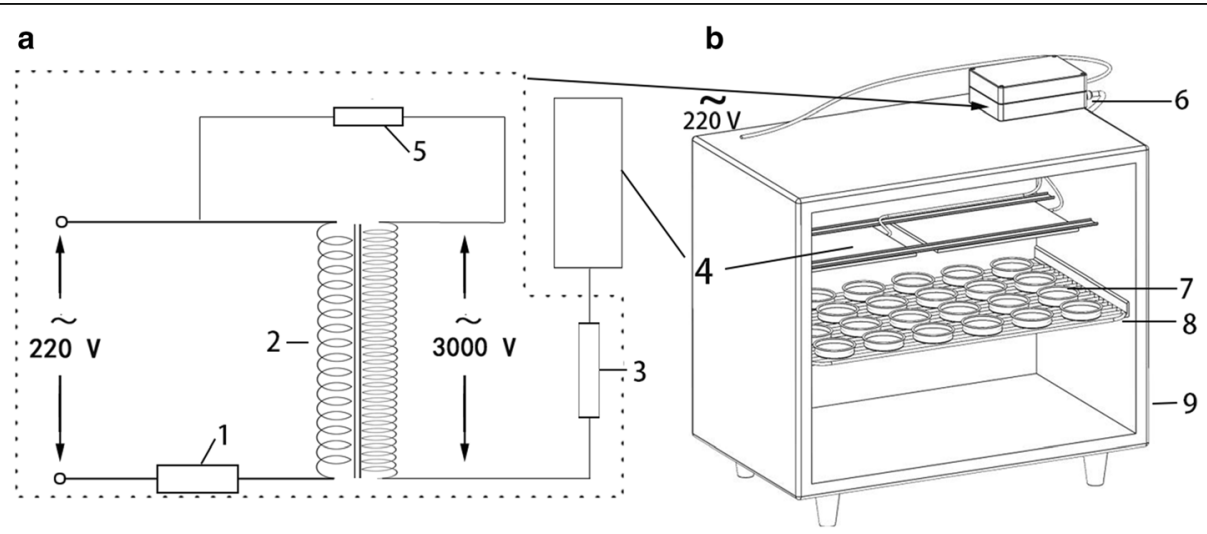

Fig. 1 Schematic diagrams of the alternating electric field (a) and a refrigerator equipped with the alternating electric field (b). 1: input controller; 2: transformer; 3: output controller; 4: discharge plate; 5: feedback control circuit; 6: alternating electric field generator; 7: petri dishes; 8: sample holder; 9: refrigerator 


\section{Cultivation on nutrient agar plates}

Microbial isolates were grown on nutrient agar plates because of its extensive use in microbiological studies and relatively definite components. Fresh bacterial cultures were prepared from a glycerol stock culture. After cultivation at $7{ }^{\circ} \mathrm{C}$ for 3 days, a single colony on nutrient agar plate was randomly chosen to prepare a bacterial suspension in sterile peptone saline. After serial dilution, $100 \mu \mathrm{L}$ of the appropriate dilutions (approx. 3,000 CFU/mL) were spread onto nutrient agar plates and were incubated at $7{ }^{\circ} \mathrm{C}$ in either a control refrigerator or a refrigerator equipped with the MEF system. MEF-treated samples were placed on holders and continuously exposed to $\operatorname{MEF}(20 \mathrm{~V} / \mathrm{cm})$ throughout the cultivation period (Fig. 1b).

\section{Microbial growth analysis}

Microbial growth of MEF-treated and control cultures was first evaluated by observing the full biomass development on nutrient agar plates as described by Ercolini et al [24]. Because of the low growth rate at cold temperatures, only cultures incubated for 3,4 , and 5 days were used.

Culture growth was also determined by monitoring the population using plating procedures. Plated cultures were suspended in $4 \mathrm{~mL}$ of peptone saline [22], serially diluted, replated on nutrient agar, and then colonies were counted after incubation at $7{ }^{\circ} \mathrm{C}$ for 3 days $[16,33]$. Three plates were prepared for daily test for each group.

\section{Dehydrogenase activity assay}

Dehydrogenase activity was assayed by MTT (3-(4, 5dimethylthiazol-2-yl)-2, 5-diphenyltetrazolium bromide; Beyotime Biotechnology, Jiangsu China) analysis described by Wang et al. [34] with slight modifications. Briefly, 3-, 4, or 5-day microbial cultures were diluted to an $\mathrm{OD}_{600}$ of 0.2 in fresh nutrient broth. A $200 \mu \mathrm{L}$ aliquot of the cell suspension was then mixed with $20 \mu \mathrm{L}$ MTT solution (5 $\mathrm{mg} / \mathrm{mL}$ in sterilized water) and incubated for $20 \mathrm{~min}$ at 25 ${ }^{\circ} \mathrm{C}$. After centrifugation at 12,000 rpm for $1 \mathrm{~min}$, pelleted cell-formazan crystal complexes were transferred into glass test tubes using $2.5 \mathrm{~mL}$ of dimethyl sulfoxide (DMSO, Sinopharm, China). The $\mathrm{OD}_{550}$ values of the mixtures were measured with a Universal Microplater Reader (Molecular Devices, Sunnyvale, CA) at 10-15 min. Three plates per group were prepared for each test.

Dehydrogenase activity is expressed in MTT reduction units (MRU). One MRU is defined as an $A_{550}$ value of 1.0 produced by the dissolved formazan crystals from cells incubated in LB medium at $7{ }^{\circ} \mathrm{C}$ in $20 \mathrm{~min}$ [34].

\section{Intracellular ATP levels determination}

Intracellular ATP levels were measured using a firefly luciferase-based bioluminescence ATP Assay Kit (Beyotime
Biotechnology). Cell suspensions prepared from 1 plate was diluted to an $\mathrm{OD}_{600}$ of 0.2 and centrifuged at 12,000 rpm for $5 \mathrm{~min}$ at $4{ }^{\circ} \mathrm{C}$. The obtained cell pellets were used to prepare intracellular ATP solution according to the supplier's instructions. Cells were mixed with lysis solution and boiled for 2 min to release ATP and to inactivate endogenous ATPase $[35,36]$. Then, $20 \mu \mathrm{L}$ ATP extraction and $100 \mu \mathrm{L}$ ATP detection solutions were mixed to prepare the luminescent reaction solution.

Luminance (RLU) was recorded using Hidex plate Chameleon ${ }^{\text {TM }}$ V. (Finland) and linearly related to the ATP concentration.

\section{$\beta$-Galactosidase activity assay}

$\beta$-Galactosidase activity was measured according to Gobinath and Prapulla [37] with some modifications. Cultures grown on 1 agar plate supplemented with $1 \%$ lactose were suspended in $4 \mathrm{~mL}$ phosphate buffered saline (PBS). The $\mathrm{OD}_{600}$ of these cultures was measured and the suspension were centrifuged at $15,000 \mathrm{rpm}$ for 5 min. $\beta$-Galactosidase activity in the resulting supernatant was determined by mixing $1 \mathrm{~mL}$ supernatant and $0.2 \mathrm{~mL}$ ONPG ( $4 \mathrm{mg} / \mathrm{mL}, o$-nitrophenyl- $\beta$-D-galactopyraniside). The reaction was terminated after incubation at $25{ }^{\circ} \mathrm{C}$ for $20 \mathrm{~min}$ by adding $0.5 \mathrm{~mL} 1 \mathrm{M} \mathrm{Na}_{2} \mathrm{CO}_{3}$. The optical density of the reaction solution was recorded at $420 \mathrm{~nm}$ $\left(\mathrm{OD}_{420}\right)$ and $550 \mathrm{~nm}\left(\mathrm{OD}_{550}\right)$, as previously described [38]. $\beta$-Galactosidase activity was calculated in Miller Units that describe the change in $\mathrm{OD}_{420} / \mathrm{min} / \mathrm{mL}$ of cells/OD 600 [39].

\section{Microscopic observations}

Control and MEF-treated cultures were observed using a scanning electron microscope (SEM; S570, Hitachi, Japan) and a transmission electron microscope (TEM; $\mathrm{H}-7500$, Hitachi). Cultures grown on nutrient agar plates for 3 days were rinsed 3 times with sterilized distilled water. After centrifugation at 15,000 rpm for $5 \mathrm{~min}$, cell pellets were suspended and fixed in glutaraldehyde (3\% aqueous solution). Other steps employed to prepare samples for SEM and TEM were carried out according to the methods described by Racyte and Zituni $[1,40]$.

\section{Statistical analysis}

The effect of MEF on $P$. fragi growth on nutrient agar plates at refrigeration temperature was evaluated by three independent experiments. The obtained data were processed with the data module of the Statistical Package for Social Science (IBM SPSS Statistics 19) for Windows and assessed with $t$-tests. A significant difference between the treated and control groups was defined as a $p$ value $<0.05$. 


\section{Results and Discussion}

Isolation and identification of psychrotrophic bacteria from meat samples

After repeated isolation and purification, a total of 25 isolates were obtained from the pork samples. All purified isolates formed visible colonies within 3 days at $7{ }^{\circ} \mathrm{C}$, indicating their adaptation to the refrigeration temperature. These colonies produced the intense fruity odor that is characteristic of pseudomonads, suggesting that these isolates might be $P$. fragi $[17,21]$.

16S DNA sequencing revealed that the 25 isolates all shared 99\% identity with $P$. fragi isolate $7 \mathrm{U}$ (Accession No.: LK391544) [41]. The 16S rDNA sequence was deposited in GenBank as KT443784 and the isolate designated as $P$. fragi MC16. These sequencing results indicate that $P$. fragi is primarily responsible for the spoilage of fresh meat stored at refrigeration temperatures. Although many microorganisms are associated with meat spoilage, few species are able to grow at the low temperatures used to preserve perishable foods [12, 15, 16, 18, 22, 24]. Several Pseudomonas species (e.g., P. fragi, P. lundensis, P. fluorescens, and P. putida) have been frequently identified as major spoilage agents in fresh pork, beef, and mutton [12, 17, 21, 23, 24, 42], but only $P$. fragi was isolated from meat samples in this study. Sample storage and processing conditions might have favored $P$. fragi growth by eliminating other spoilage-related species [22]. Additionally, the biotype diversity of $P$. fragi might contribute to this result because different molecular types of $P$. fragi might behave similarly as meat spoilers [21].

\section{Growth of $P$. fragi MC16 on nutrient agar plates}

Control and MEF-treated cultures could be clearly differentiated by observing biomass development. MEF-treated colonies were smaller than untreated colonies after 3 days of growth (Fig. 2). However, the size difference gradually decreased after 4 and 5 days of incubation.

Total viable counts of the control and MEF-treated cultures were determined to quantify the effect of MEF treatment on the growth of $P$. fragi MC16. Total viable counts of the treated and untreated cultures were significantly different $(p<0.05)$ after 3 and 4 days of growth (Fig. 3). Similar to the qualitative biomass development assessments, no significant difference in quantitative biomass between the two groups was found after 5 days of incubation. These results are consistent with a previous study by Loghavi [6], indicating that P. fragi MC16 responds differently to MEF exposure during different growth phases.

Changes in the susceptibility of $P$. fragi MC16 on nutrient agar plates to MEF treatment can be attributed to limited nutrient diffusion in the solid matrix and culture age. Previous studies suggested that MEF treatment at lower frequencies could cause temporary, non-lethal membrane permeabilization [9, 43]. For cells grown in liquid medium, increased permeability enhances nutrient diffusion across cell membranes and reduced lag phases are observed [6]. However, nutrient diffusion in solid medium is relatively low. As a result, temporary permeabilization on nutrient agar plates causes sublethal damage rather than rapid nutrient uptake. Therefore, retarded cell growth was observed in this study. Additionally, older
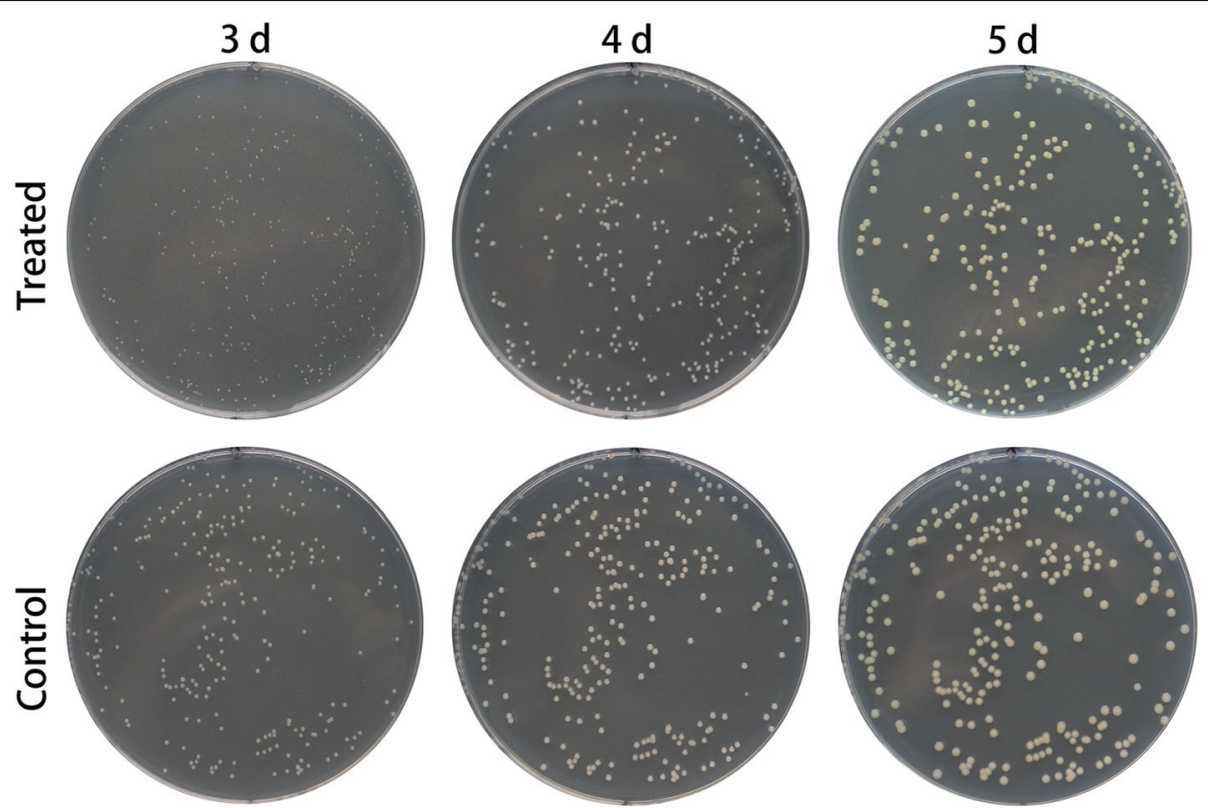

Fig. 2 P. fragi MC16 biomass development on nutrient agar plates for different incubation durations. An identical petri dish was employed on different days for each group 


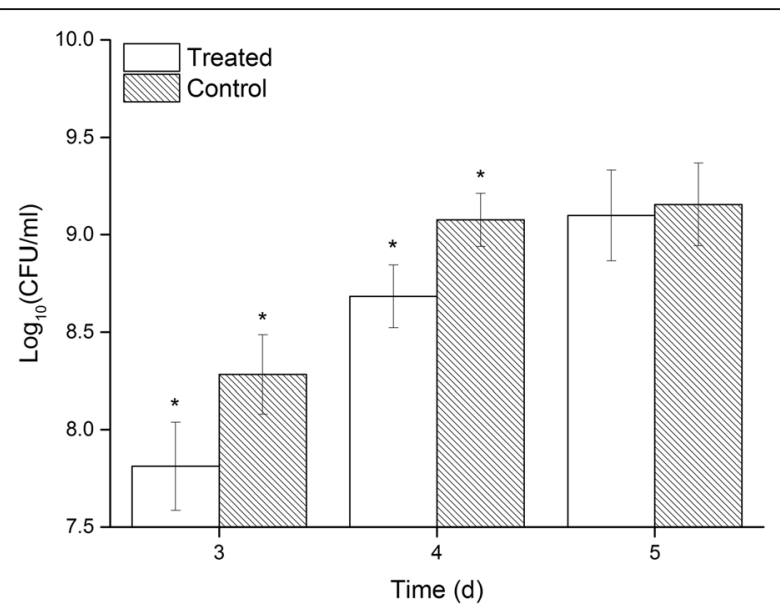

Fig. 3 Changes in total viable counts of $P$. fragi MC16 grown on nutrient agar plates for different times at $7{ }^{\circ} \mathrm{C}$ * ${ }^{*}$ indicates a significant difference from the control group, $p<0.05$

cultures have decreased protein to lipid ratios in membranes $[9,43]$, causing decreased membrane fluidity and susceptibility to external MEF treatment. Thus, biomass recovered later during incubation.

\section{The effect of MEF treatment on P. fragi MC16 metabolic activity}

MEF is an environmental stress to which microorganisms can adapt, similar to cold, heat, and pressure [3, 36]. Microorganisms can modulate their metabolism to cope with sublethal stressors $[44,45]$ and may enter different growth phases that alter their susceptibility to the stress $[6,9]$. Therefore, investigating metabolic changes is one method to characterize microbial stress responses. Dehydrogenases are key enzymes involved in the oxidative activities of various organisms, thus dehydrogenase activity reflects the metabolic state of the organism [36, 46]. We measured intracellular dehydrogenase activity during MEF treatment to characterize the metabolic state of $P$. fragi MC16. MEF-treatment significantly increased intracellular dehydrogenase activity for treated cultures after 3 and 4 days $(p<0.05$; Fig. 4). Intracellular dehydrogenase activity of MEF-treated cultures after 3 and 4 days was 2.5- and 1.8times higher than the control groups, respectively. However, dehydrogenase activity decreased after 5 days of treatment such that the enzyme activity in MEF-treated cultures was only 1.2-fold higher than in control cultures. This difference was not significant.

Increased dehydrogenase activity is generally associated with the energy-consuming microbial stress response $[44,46]$. This response has been previously observed in S. aureus exposed to high osmolarity or high pressure [47]. We found that increased dehydrogenase activity was readily observed when $P$. fragi cultures were treated with MEF. Due to the sublethality of MEF,

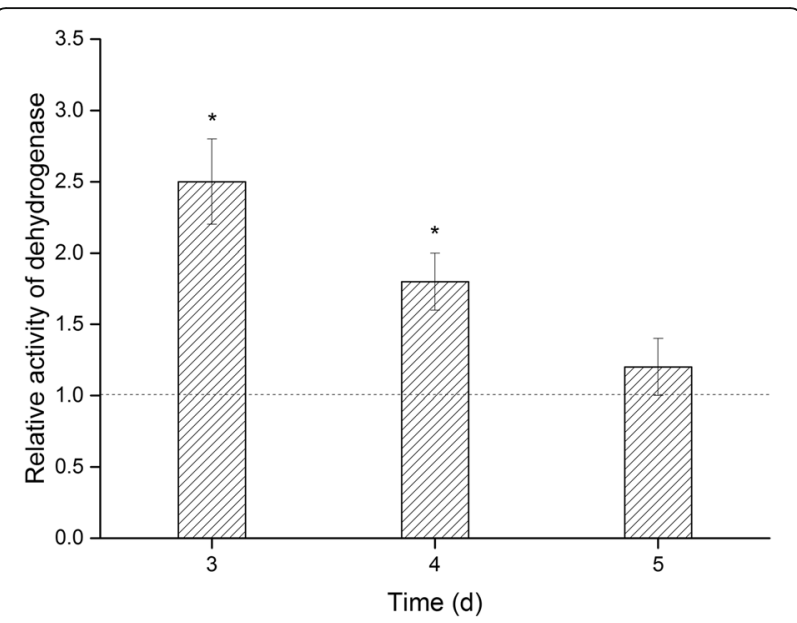

Fig. 4 The effect of MEF on intracellular dehydrogenase activity. Dehydrogenase activity is expressed in relative units as the ratio of dehydrogenase activity of the treated group to the control group. Error bars represent standard error. The dashed line indicates a ratio of one (where values of the treated group are equal to the control group). ${ }^{*}$ indicates significant difference from the control group, $p<0.05$

microorganisms exposed to this field must repair injured membranes [48]. Additionally, MEF treatment may impact the conformation of cellular proteins [9]. To restore normal protein conformations and survive these conditions, microorganisms must modulate gene expression and modify metabolism to engage adaptive cellular mechanisms [49]. All metabolic changes induced by MEF treatment reflected higher metabolic investment, which is generally characterized by increased dehydrogenase activity and ATP level [36]. These metabolic changes may have diminished after 5 days of treatment and incubation because the cells activated adaptive mechanisms and modulated gene expression to manage the stressor.

\section{The effect of MEF on intracellular ATP concentration}

ATP is a direct participant in many cellular metabolic processes [36]. Therefore, changes in ATP concentration may characterize the metabolic state during MEF treatment more specifically than changes in dehydrogenase activity. As shown in Fig. 5, MEF treatment increased intracellular ATP content. ATP concentrations in cultures treated for 3,4 , and 5 days were 1.5-, 1.4-, and 1.1-times higher than control cultures, respectively. Other forms of environmental stress (e.g., heat, pressure, starvation, $\mathrm{pH}$, and irradiation) have been previously reported to increase ATP concentration in microorganisms [50], suggesting that MEF-treatment causes a similar cellular response as these stressors. The concentration of intracellular ATP in MEFtreated cells decreased to the level of the controls after 5 days of exposure, indicating metabolic adaptation to the MEF treatment. This trend in intracellular ATP content reflects similar findings in biomass development and 


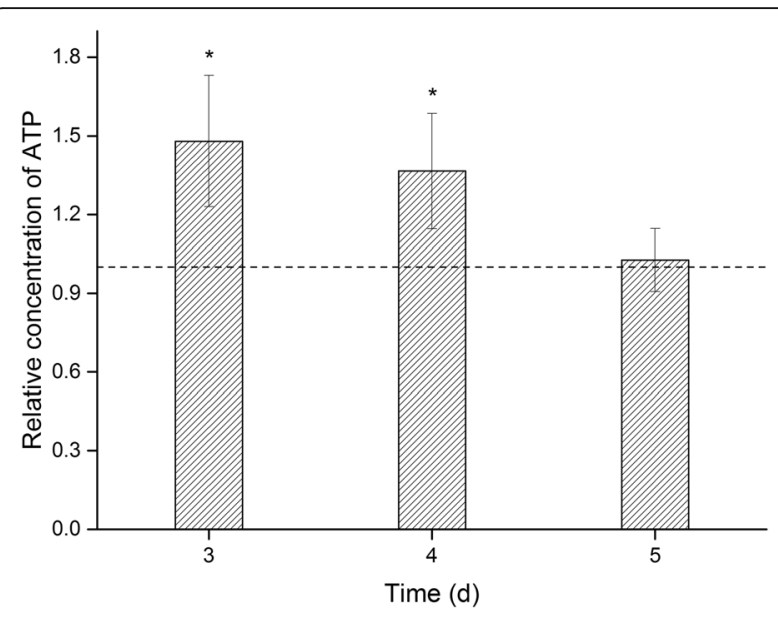

Fig. 5 The influence of MEF on intracellular ATP concentration in P. fragi. Values are presented as ratios of ATP concentration (RLU/OD ${ }_{600}$ ) in treated cultures relative to control cultures. The dashed line indicates a ratio of one (where means values of treated cultures are equal to control cultures). ${ }^{*}$ indicates a significant difference from the control cultures $(p<0.05)$

intracellular dehydrogenase activity of the treated cultures over time.

\section{The effect of MEF on inner membrane permeability}

$\beta$-Galactosidase is a large, tetrameric protein [39]. Because of its high molecular weight, presence of extracellular $\beta$-galactosidase is generally associated with a loss of cell membrane integrity [51]. Thus, the activity of extracellular $\beta$-galactosidase produced by MEF-treated and untreated cultures was quantified to indicate cell membrane alterations over time.

Extracellular $\beta$-galactosidase activity levels in treated and untreated cultures were 0.79 and 0.80 Miller Units, respectively, after 3 days of cultivation. Extracellular $\beta$ galactosidase activity levels were not significantly different between treated and untreated cultures at 3, 4, or 5 days of cultivation (Fig. 6).

These results suggest that MEF treatment did not increase cell membrane permeability, since permeabilized membranes would allow intracellular $\beta$-galactosidase to leak into extracellular space. Membrane permeabilization via MEF has been reported in several studies [6, 9, 48]; however, permeabilization is reversible and membrane integrity can be quickly reestablished [48]. Accordingly, the low levels of extracellular $\beta$-galactosidase activity observed in this study may indicate that cellular membranes were reestablished too rapidly to detect major changes. In addition, the MEF system used in this study was designed to maintain the freshness of solid cellular foods, such as meat, fish, fruits, and vegetables [32]. The MEF system was not designed to inactivate microorganisms by forming irreversible membrane permeabilization, since inactivation

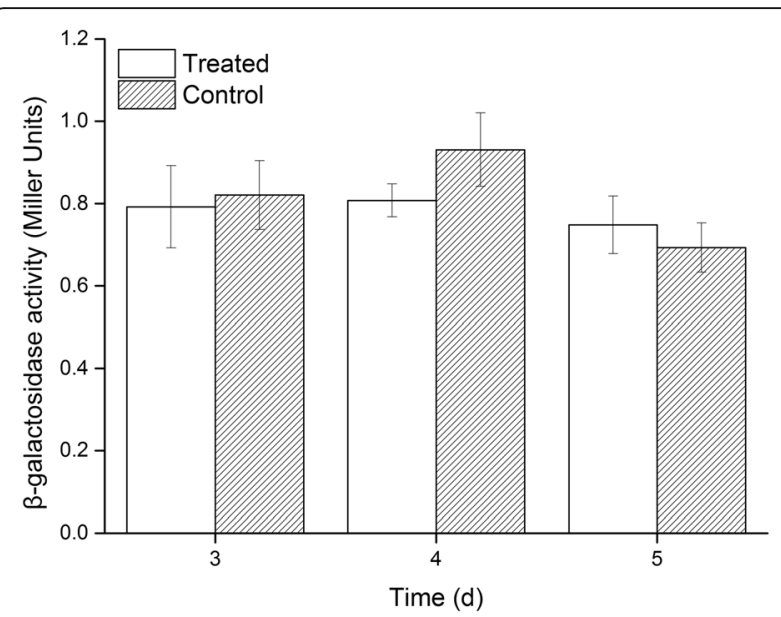

Fig. 6 Extracellular $\beta$-galactosidase activity of the treated and untreated cultures grown on nutrient agar plates for different times

would compromise the freshness and nutrition of the cellular foods that also have cell membranes [7]. Moreover, the intensity of the EMF used in this study was lower than $30 \mathrm{~V} / \mathrm{cm}$, ruling out the possibility of electroporation that was reported to occur at field intensities around $1,000 \mathrm{~V} / \mathrm{cm}[3,52]$.

\section{Morphological changes of $P$. fragi MC16 induced by MEF}

Intact cell morphology and cytology are essential for the normal growth and multiplication of microorganisms, thus alterations in microbial morphology and cytology reflect cell viability $[5,40,51]$. Microscopic observations of cultures treated for different incubation periods were conducted using SEM and TEM.

SEM observations illustrated changes in cell morphology (Fig. 7). Cultures treated with MEF for 3 days were largely intact, but showed surface indentations (indicated with arrows in Fig. 7a). Cellular debris derived from cell disintegration has been reported by previous literature $[5,40]$, but was not observed in this study. These results support the findings of the extracellular $\beta$-galactosidase activity: MEF treatment appears to have limited impact on microbial cell membranes. Microbial cells treated with MEF for 4 and 5 days could not be differentiated from control cells (Fig. 7e and f), which were characterized by smooth cell surface and uniform cell shapes. The cell morphologies of control and MEF-treated cells after 3 days of treatment may indicate that the treated cells adapted to the MEF exposure. SEM examinations of untreated cultures showed no changes in cell morphology throughout the process (Fig. 7d, e, and f).

TEM observations of MEF-treated cultures showed agglomerations of cytoplasmic materials, vacuole formations, and depressed cell membranes (indicated with arrows in Fig. 8a and b). These cellular observations are consistent with cell damage induced by continuous 


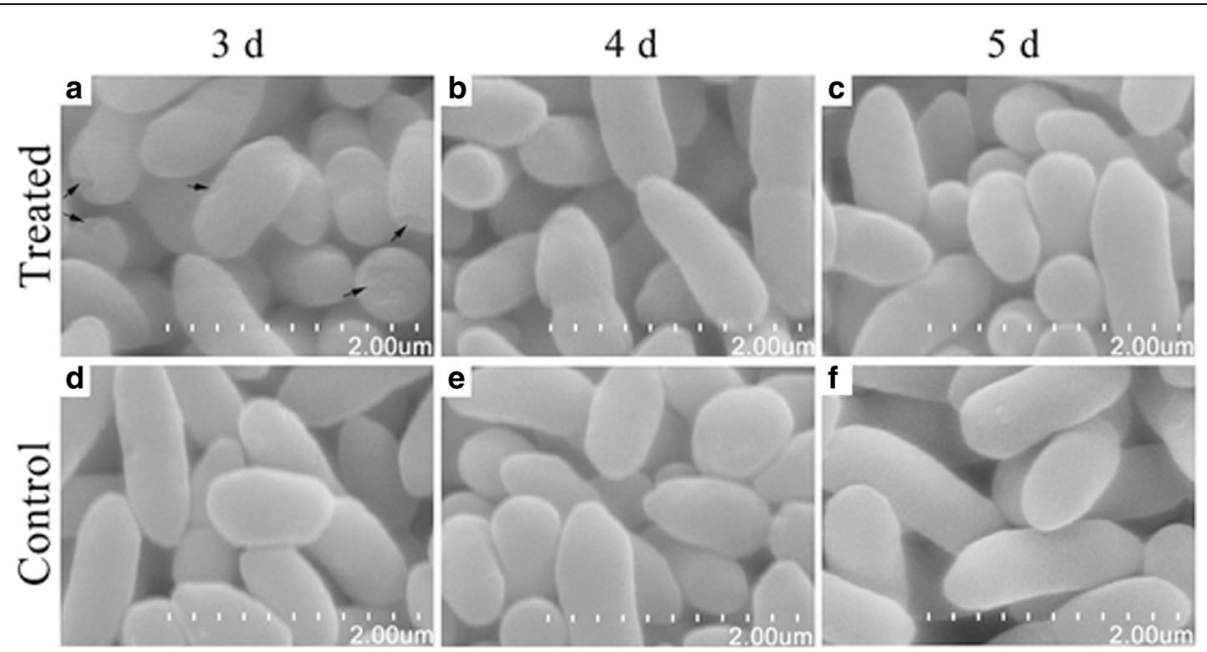

Fig. 7 Scanning electron microscope observations of $P$. fragi MC16 grown for different times. a-c Treated samples; d-f Control samples. Arrows indicate cell surface indentations

ultrasound in E. coli ATCC 11775 [53]. Nevertheless, these changes gradually disappeared when the exposure time was extended to 5 days (Fig. 8c). At this point, TEM observations of treated and control cultures (Fig. 8f) were almost identical, suggesting that the cells had completely adapted to the MEF treatment. Control cells showed regular shape and morphology, with the cytoplasm filling the entire cell envelope (Fig. 8d, e, and f).

Summarizing the observations on morphology and cytology, cultures at early growth stages might be susceptible to continuous MEF exposure; however, they subsequently recovered from these injuries as the treatment progressed. These results indicate the microbial adaptation to the MEF treatment and support previous findings that the bacterial stress response supports adaptation to adverse environments [49].

\section{Conclusions}

MEF application is a novel technology for preserving solid cellular foods. The technology can cause adverse morphological and cytological changes to microorganisms growing on a solid matrix during early cell growth stages. However, the impact of MEF application gradually weakens as cells potentially responded to the stress via modified metabolism and gene expression changes. Therefore, future research exploring the adaptive mechanisms to MEF is required before this technology can be improved to further extend the shelf life of solid cellular foodstuffs and reduce food losses caused by microorganisms.

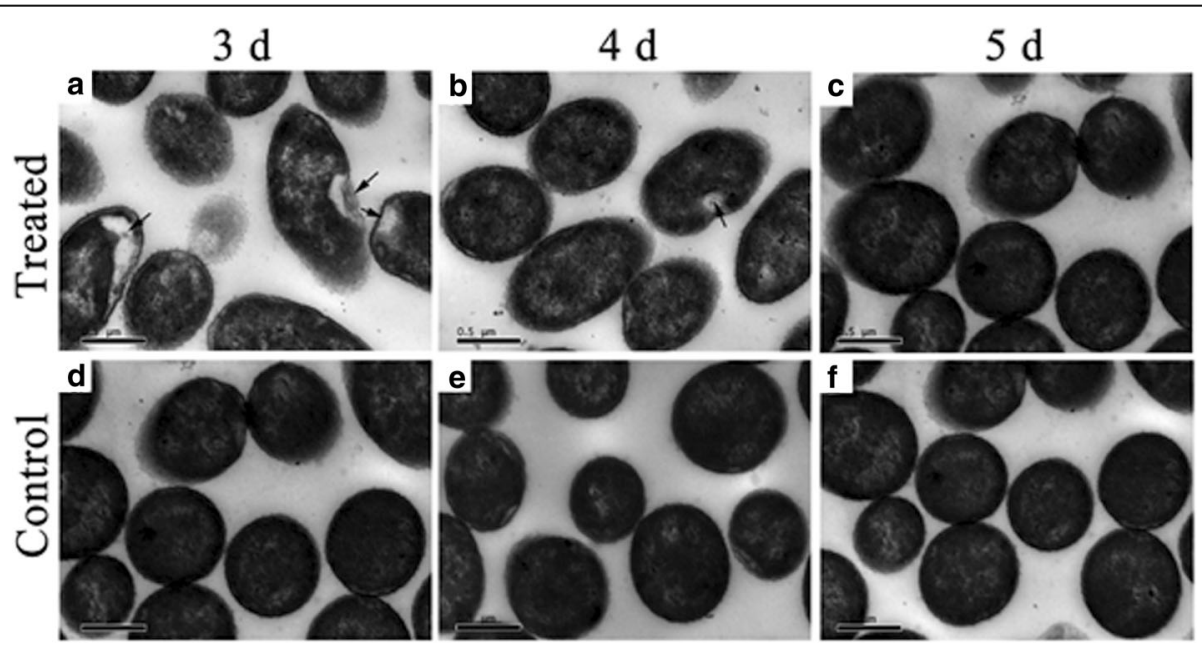

Fig. 8 Transmission electron microscope observations of $P$. fragi MC16 grown for different times. a-c Treated samples; $\mathbf{d}$-f Control samples. Arrows indicate agglomerations of intracellular contents 


\section{Abbreviations}

ATP: Adenosine triphosphate; DNA: Deoxyribonucleic acid; MEF: Moderate electric field; MRU: MTT reduction units; MTT: 3-(4, 5-dimethylthiazol-2-yl)-2, 5-diphenyltetrazolium bromide; OD: Optical density; ONPG: o-nitrophenyl- $\beta$ D-galactopyraniside; RLU: Relative luminance unit; SEM: Scanning electron microscope; TEM: Transmission electron microscope

\section{Acknowledgements}

None.

\section{Funding}

This research was supported by grants from the National Natural Science Foundation of China (No. 31501549), the Special Fund for Agro-scientific Research in the Public Interest (No. 201303083-1), the Agricultural Science and Technology Innovation Program, CAAS (No. CAAS-XTCX2016005), and the Central Public-interest Scientific Institution Basal Research Fund (No. 0032015016)

\section{Availability of data and materials}

The sequence of $P$. fragi MC16 was deposited in Genbank under accession number KT443784

\section{Authors' contributions}

WBC, $\mathrm{HHH}$, and CJZ designed the study and performed the experiments. WBC, FH, and DQZ analyzed the data. WBC and $\mathrm{HHH}$ prepared the main manuscript text under the direction of $\mathrm{HZ}$. All authors have read and approved the final manuscript.

\section{Competing interests}

The authors declare that they have no competing interests.

\section{Consent for publication}

Not applicable.

\section{Ethics approval and consent to participate}

Not applicable.

Received: 2 September 2016 Accepted: 3 February 2017

Published online: 10 February 2017

\section{References}

1. Racytea J, Bernard S, Paulitsch-Fuchsa AH, Yntema DR, Bruning H, Rijnaarts HHM. Alternating electric fields combined with activated carbon for disinfection of Gram negative and Gram positive bacteria in fluidized bed electrode system. Water Res. 2013:47(16):6395-405.

2. Racyte J, Sharabati J-A-D, Paulitsch-Fuchs AH, Yntema DR, Mayer MJJ, Bruning $\mathrm{H}$, et al. Combining fluidized activated carbon with weak alternating electric fields for disinfection. Carbon. 2011;49(15):5321-8.

3. Giladi M, Porat $Y$, Blatt A, Wasserman $Y$, Kirson ED, Dekel E, et al. Microbial growth inhibition by alternating electric fields. Antimicrob Agents Chemother. 2008;52(10):3517-22

4. Giladi M, Porat $Y$, Blatt A, Shmueli E, Wasserman $Y$, Kirson ED, et al. Microbial growth inhibition by alternating electric fields in mice with Pseudomonas aeruginosa lung infection. Antimicrob Agents Chemother. 2010;54(8):3212-8

5. Valle A, Zanardini E, Abbruscato P, Argenzio P, Lustrato G, Ranalli G, et al Effects of low electric current (LEC) treatment on pure bacterial cultures. J Appl Microbiol. 2007:103(5):1376-85.

6. Loghavi L, Sastry SK, Yousef AE. Effect of moderate electric field frequency on growth kinetics and metabolic activity of Lactobacillus acidophilus. Biotechnol Prog. 2008;24:148-53.

7. Ito T, Kawwamura T, Nakagawa A, Yamazaki S, Syuto B, Takaki K Preservation of fresh food using AC electric field. J Adv Oxid Technol. 2014; 7(2):249-53.

8. Romel R, Mohamed HMH, Sastry SK. Inactivation kinetics of Bacillus coagulans spores under ohmic and conventional heating. LWT-Food Sci Technol. 2013:54(1):194-8.

9. Loghavi L, Sastry SK, Yousef AE. Effect of moderate electric field frequency and growth stage on the cell membrane permeability of Lactobacillus acidophilus. Biotechnol Prog. 2009;25(1):85-94.
10. Dave D, Ghaly AE. Meat spoilage mechanisms and preservation techniques: a critical review. Am J Agric Biol Sci. 2011:6(4):486-510.

11. Zhou G, Xu X, Liu Y. Preservation technologies for fresh meat - A review. Meat Sci. 2010;86(1):119-28.

12. Doulgeraki Al, Ercolini D, Villani F, Nychas G-JE. Spoilage microbiota associated to the storage of raw meat in different conditions. Int J Food Microbiol. 2012;157(2):130-41.

13. Jääskeläinen E, Hultman J, Parshintsev J, Riekkola M-L, Björkroth J. Development of spoilage bacterial community and volatile compounds in chilled beef under vacuum or high oxygen atmospheres. Int J Food Microbiol. 2016:223:25-32

14. Jones TH, Vail KM, McMullen LM. Filament formation by foodborne bacteria under sublethal stress. Int J Food Microbiol. 2013:165(2):97-110.

15. Neubeck M, Baurb C, Krewinkel M, Stoeckel M, Kranz B, Stressler T, et al. Biodiversity of refrigerated raw milk microbiota and their enzymatic spoilage potential. Int J Food Microbiol. 2015;211:57-65.

16. Morsy MK, Zór K, Kostesha N, Alstrøm TS, Heiskanen A, El-Tanahi H, et al. Development and validation of a colorimetric sensor array for fish spoilage monitoring. Food Control. 2016:60:346-52

17. Casaburi A, Piombino P, Nychas G-J, Villani F, Ercolini D. Bacterial populations and the volatilome associated to meat spoilage. Food Microbiol. 2015;45:83-102.

18. Hammond ST, Brown JH, Burger JR, Flanagan TP, Fristoe TS, Mercado-Silva $\mathrm{N}$, et al. Food spoilage, storage, and transport: Implications for a sustainable future. Bioscience. 2015;65(8):758-68.

19. Argyri AA, Mallouchos A, Panagou EZ, Nychas G-JE. The dynamics of the HS/SPME-GC/MS as a tool to assess the spoilage of minced beef stored under different packaging and temperature conditions. Int J Food Microbiol. 2015;193:51-8

20. Selvakumar G, Joshi P, Nazim S, Mishra P, Bisht J, Gupta H. Phosphate solubilization and growth promotion by Pseudomonas fragi CS11RH1 (MTCC 8984), a psychrotolerant bacterium isolated from a high altitude Himalayan rhizosphere. Biologia (Bratisl). 2009;64(2):239-45.

21. Ercolini D, Casaburi A, Nasi A, Ferrocino I, Monaco RD, Ferranti P, et al. Different molecular types of Pseudomonas fragi have the same overall behaviour as meat spoilers. Int J Food Microbiol. 2010:142:120-31.

22. Ercolini D, Russo F, Blaiotta G, Pepe O, Mauriello G, Villani F. Simultaneous detection of Pseudomonas fragi, P. lundensis, and $P$. putida from meat by use of a multiplex PCR assay targeting the carA gene. Appl Environ Microbiol. 2007:73(7):2354-9.

23. Storia AL, Ferrocino I, Torrieri E, Monaco RD, Mauriello G, Villani F, et al. A combination of modified atmosphere and antimicrobial packaging to extend the shelf-life of beefsteaks stored at chill temperature. Int J Food Microbiol. 2012;158(3):186-94.

24. Ercolini D, Russo R, Nasi A, Ferranti P, Villani F. Mesophilic and psychrotrophic bacteria from meat and their spoilage potential in vitro and in beef. Appl Environ Microbiol. 2009:75(7):1990-2001.

25. Nychas G-JE, Skandamis PN, Tassou CC, Koutsoumanis KP. Meat spoilage during distribution. Meat Sci. 2008:78(1-2):77-89.

26. Casaburi A, Nasi A, Ferrocino I, Monaco RD, Mauriello G, Villani F, et al. Spoilage-related activity of Carnobacterium maltaromaticum strains in airstored and vacuum-packed meat. Appl Environ Microbiol. 2011;77(20):7382-93.

27. Zhao F, Zhou G, Ye K, Wang S, Xu X, Li C. Microbial changes in vacuumpacked chilled pork during storage. Meat Sci. 2015;100:145-9.

28. Pacholewicz E, Liakopoulos A, Swart A, Gortemaker B, Dierikx C, Havelaar A, et al. Reduction of extended-spectrum- $\beta$-lactamase- and AmpC- $\beta$ lactamase-producing Escherichia coli through processing in two broiler chicken slaughterhouses. Int J Food Microbiol. 2015;215:57-63.

29. Pacholewicz E, Swart A, Schipper M, Gortemaker GG, Wagenaar JA, Havelaar $\mathrm{AH}$, et al. A comparison of fluctuations of Campylobacter and Escherichia coll concentrations on broiler chicken carcasses during processing in two slaughterhouses. Int J Food Microbiol. 2015;205:119-27.

30. Cody WL, Wilson JW, Hendrixson DR, Mclver KS, Hagman KE, Ott CM, et al. Skim milk enhances the preservation of thawed $-80{ }^{\circ} \mathrm{C}$ bacterial stocks. J Microbiol Methods. 2008;75(1):135-8.

31. Kermanshahi RK, Sailani MR. Effect of static electric field treatment on multiple antibiotic-resistant pathogenic strains of Escherichia coli and Staphylococcus aureus. J Microbiol Immunol Infect. 2005:38(6):394-8.

32. Takayuki K, Kanako K. In: Freshness keeping apparatus using space potential generator. JP5683032. Japan; 2015. Available online: http://www. freepatentsonline.com/JP5683032B1.html. 
33. Ko W, Yang S, Chang C, Hsieh C. Effect of adjustable parallel high voltage electrostatic field on the freshness of tilapia (Orechromis niloticus) during refrigeration. LWT-Food Sci Technol. 2016;66:151-7.

34. Wang $H$, Cheng $H$, Wang F, Wei D, Wang X. An improved 3-(4,5dimethylthiazol-2-yl)-2,5-diphenyl tetrazolium bromide (MTT) reduction assay for evaluating the viability of Escherichia coli cells. J Microbiol Methods. 2010;82(3):330-3.

35. Jiang X, Yu X, Fan J, Guo L, Zhu C, Jiang W, et al. RFT2 is overexpressed in esophageal squamous cell carcinoma and promotes tumorigenesis by sustaining cell proliferation and protecting against cell death. Cancer Lett. 2014:353(1):78-86.

36. Filipiča J, Kraigher B, Tepuš B, Kokol V, Mandic-Mulec I. Effects of low-density static magnetic fields on the growth and activities of wastewater bacteria Escherichia coli and Pseudomonas putida. Bioresour Technol. 2012;120:225-32.

37. Gobinath D, Prapulla SG. Permeabilized probiotic Lactobacillus plantarum as a source of $\beta$-galactosidase for the synthesis of prebiotic galactooligosaccharides. Biotechnol Lett. 2014;36(1):153-7.

38. Griffith $\mathrm{KL}$, Richar $\mathrm{E}$, Wolf J. Measuring $\beta$-galactosidase activity in bacteria: cell growth, permeabilization, and enzyme assays in 96-well arrays. Biochem Biophys Res Commun. 2002;290:397-402.

39. Li W, Zhao X, Zou S, Ma Y, Zhang K, Zhang M. Scanning assay of $\beta$ galactosidase activity. Appl Biochem Microbiol. 2012;48(6):603-7.

40. Zituni D, Schutt-Gerowitt H, Kopp M, Kronke M, Addicks K, Hoffmann C, et al. The growth of Staphylococcus aureus and Escherichia coli in low-direct current electric fields. Int J Oral Sci. 2014;6(1):7-14.

41. Røder HL, Raghupathi PK, Herschend J, Brejnrod A, Knøchel S, Sørensen SJ, et al. Interspecies interactions result in enhanced biofilm formation by cocultures of bacteria isolated from a food processing environment. Food Microbiol. 2015;51:18-24.

42. Lerma LL, Benomar N, Gálvez A, Abriouel H. Prevalence of bacteria resistant to antibiotics and/or biocides on meat processing plant surfaces throughout meat chain production. Int J Food Microbiol. 2013;161(2):97-106.

43. Loghavi L, Sastry SK, Yousef AE. Effect of moderate electric field on the metabolic activity and growth kinetics of Lactobacillus acidophilus. Biotechnol Bioeng. 2007;98(4):872-81.

44. Velasco-Alvarez N, González I, Damian-Matsumura P, Gutiérrez-Rojas M. Enhanced hexadecane degradation and low biomass production by Aspergillus niger exposed to an electric current in a model system. Bioresour Technol. 2011;102(2):1509-15.

45. Thrash JC, Coates JD. Review: direct and indirect electrical stimulation of microbial metabolism. Environ Sci Technol. 2008:42(11):3921-31.

46. Danevčič T, Stopar D. Asymmetric response of carbon metabolism at high and low salt stress in Vibrio sp. DSM14379. Microb Ecol. 2011;62(1):198-204.

47. Vilhelmsson O, Miller K. Synthesis of pyruvate dehydrogenase in Staphylococcus aureus is stimulated by osmotic stress. Appl Environ Microbiol. 2002:68(5):2353-8.

48. Machado LF, Pereira RN, Martins RC, Teixxeira JA, Vicente AA. Moderate electric fields can inactivate Escherichia coli at room temperature. J Food Eng. 2010;96(4):520-7.

49. Boor KJ. Bacterial stress responses: what doesn't kill them can make them stronger. PLoS Biol. 2006;4(1), e23.

50. Karu T, Pyatibrat L, Kalendo G. Irradiation with He-Ne laser increase ATP level in cells cultivated in vitro. J Photochem Photobiol B. 1995;27:219-23.

51. Jain S, Sharma A, Basu B. Vertical electric field induced bacterial growth inactivation on amorphous carbon electrodes. Carbon. 2015;81:193-202.

52. Amarjargal A, Tijing LD, Ruelo MTG, Park C-H, Pant HR, Iv FPV, et al. Inactivation of bacteria in batch suspension by fluidized ceramic tourmaline nanoparticles under oscillating radio frequency electric fields. Ceram Int. 2013;39(2):2141-5.

53. Moody A, Marx G, Swanson BG, Bermúdez-Aguirre D. A comprehensive study on the inactivation of Escherichia coli under nonthermal technologies: High hydrostatic pressure, pulsed electric fields and ultrasound. Food Control. 2014:37:305-14

\section{Submit your next manuscript to BioMed Central and we will help you at every step:}

- We accept pre-submission inquiries

- Our selector tool helps you to find the most relevant journal

- We provide round the clock customer support

- Convenient online submission

- Thorough peer review

- Inclusion in PubMed and all major indexing services

- Maximum visibility for your research

Submit your manuscript at www.biomedcentral.com/submit

) Biomed Central 